\title{
UN LIBRO FUNDAMENTAL SOBRE LA POESÍA POPULAR ESPAÑOLA DE TIPO TRADICIONAL*
}

\section{Maximiano Trapero}

El título de este libro responde con absoluta fidelidad a su contenido: en él se trata de lírica popular, o si se quiere -porque sobre esta denominación no hay acuerdo y sí preferencias- de lírica tradicional. Y aunque no se diga en el título, se trata en él tanto de lírica antigua como de lírica moderna. En realidad, el libro representa un recorrido muy abarcador por toda la historia de la literatura española en el campo de la lírica de tipo popular, desde las jarchas hasta las coplas actuales (sobre ello volveremos).

E igualmente el subtítulo da cuenta exacta del motivo del libro. Lo que ahora se publica es el resultado de un ciclo de conferencias (o de "lecciones") que, en marzo de 1996, el Departamento de Literatura Española y la Facultad de Filología de la Universidad de Sevilla organizaron en homenaje al insigne arabista e figura señera de la inteligencia española que fue Don Emilio García Gómez, muerto un año antes, en mayo de 1995, y que era Doctor honoris causa de la Universidad de Sevilla.

El editor es el mismo que antes fue coordinador del ciclo de conferencias que están en el origen del libro: Pedro M. Piñero Ramírez, director del Departamento de Literatura de la Universidad de Sevilla y reconocido especialista en la literatura de los Siglos de Oro, y muy particularmente en la literatura de tipo tradicional (romancero y cancionero).

Don Emilio García Gómez se hizo merecedor a muchos homenajes, sin duda, pero pocos autores merecerían tanto como él uno que estuviera centrado en la lírica de tipo tradicional, porque él no sólo fue el maestro indiscutible de las jarchas, sino uno de los que inspiró y demostró fehacientemente la marca de tradicional que caracteriza a gran parte de la lírica popular española a lo largo de su historia. Él fue quien dijo, en frase muy breve y cierta, que la historia de la poesía popular española no es sino "diez siglos de coplas", un mismo bloque compacto y homogéneo, de características en todo sensiblemente iguales, que viene durando desde finales del siglo IX. En el principio fueron las jarchas; después, los zéjeles, y desde el siglo XV, los villancicos, en todas sus variedades; después, desde el siglo XVII, las coplas de todo género; y, por fin, lo que sin dejar de ser coplas han acabado por denominarse cantares. La inspiración y el sentir popular se han acomodado en cada

\footnotetext{
* Piñero Ramírez, Pedro M (ed.): Lírica Popular / Lírica Tradicional (Lecciones en homenaje a Don Emilio García Gómez). Sevilla: Universidad de Sevilla y Fundación Machado, 1998, 302 págs. ISBN 84-472-0434-0.
} 
tiempo a unas formas poéticas cambiantes, pero el motivo poético ha sido el mismo. La lírica de las viejas coplillas romances [las jarchas] -dejó dicho nuestro máximo arabista- no es un islote. Unida sin solución de continuidad a las coplillas en árabe vulgar, como éstas luego a los villancicos, y éstos, a la vez, a las coplas que todavía se componen en todos los ámbitos de la Península Ibérica y aun de todo el Mundo Hispánico, forman entre todos un enorme y macizo cuerpo lírico.

De eso trata el libro que reseñamos: de un recorrido por el tiempo y por los géneros que a lo largo de la historia han constituido la lírica popular española de tipo tradicional. Y ya tenemos aquí unidos en una misma frase los dos términos que definen este tipo de poesía: es popular y es tradicional, a la vez y selectivamente; porque no toda la poesía popular tiene ese carácter, y porque también existe una tradición en la poesía culta.

El carácter de "panorama" de la lírica popular tradicional que el libro tiene es digno de destacarse, pues le da un valor añadido. En él ofrecen sus opiniones y exponen sus investigaciones más recientes algunos de los máximos especialistas que tiene esta temática en el momento actual. Podrá decirse que no están todos, pero no que los que están no lo sean. Desde los que dedican sus estudios a la lírica antigua, medieval (las jarchas y las cantigas de amigo), hasta los que centran su atención en la lírica popular actual, pasando por los que estudian el cancionero de los Siglos de Oro y los que toman un punto de vista comparativo, fijándose en las relaciones y pervivencias de la lírica antigua en la poesía moderna y actual.

La organización del libro es impecable, desde él punto de vista cronológico. A una Presentación del editor Pedro Piñero, que explica los motivos y características del libro, le sigue una evocación de Francisco López Estrada sobre los estudios de lírica medieval que hizo el autor homenajeado: Don Emilio García Gómez.

Dos estudios siguen después centrados en las jarchas: uno muy abarcador de quien es ahora, muerto Don Emilio, el máximo especialista en ellas, Álvaro Galmés de Fuentes, y otro de Rodrigo de Zayas referido a la música con que debían cantarse, a partir de la melodía de una cancioncilla mozárabe conservada en el Quinientos.

Las cantigas de amigo portuguesas, como crisol de una rica tradición poética europea, son estudiadas después por Pilar Lorenzo Gradín, profesora de la Universidad de Santiago de Compostela.

Siguen cuatro estudios referidos a la poesía conservada en los cancioneros de los siglos XV, XVI y XVII. El de Carlos Alvar, catedrático de la Universidad de Alcalá, se centra en un tema de gran importancia: las relaciones y cruces que tuvo la lírica popular con la poesía cortesana en el Medievo. El de Vicenç Beltrán, catedrático de la Universidad de Barcelona, trata de los problemas que plantea la edición de los textos de lírica popular antigua, conservados en su inmensa mayoría en cancioneros y otras publicaciones de los siglos áureos, a partir del siglo $\mathrm{XV}$, pero no de manera independiente, sino en medio de glosas cultas y rodeados de otros metros a quienes acompañaban. José María Alín, autoridad indiscutible en el tema de la poesía de tipo tradicional, centra su estudio en las canciones de carácter popular contenidas (y referenciadas) en la obra de Francisco de 
Salinas (autor más famoso en la historia de la literatura por la Oda que su música inspiró a Fray Luis que por sus "Siete Libros de Música", amplio y serio tratado de teoría musical). Finalmente, la gran investigadora mexicana Margit Frenk, máxima autoridad indiscutible en la poesía popular antigua, dedica su estudio en esta ocasión a un tema de gran trascendencia: los símbolos naturales que aparecen en las viejas canciones populares hispánicas (la luna, el olivo, la garza, el pavo real, la fuente, el ciervo...), y que no se dan en la poesía culta. El conocimiento de este mundo simbólico, del que tan impregnada está la poesía popular, es trascendental para su comprensión cabal: una coplilla antigua nos atrae por su sencillez, nos cautiva por su musicalidad, nos seduce por lo que sugiere, más que por lo que dice, pero sólo nos maravilla cuando comprendemos su significado simbólico, más allá del mero significado denotativo de sus palabras. Y es éste uno de los campos en los que las aportaciones de Margit Frenk resultan absolutamente fundamentales, por el dominio que tiene de todo el corpus de la lírica popular antigua.

Dos trabajos siguen después dedicados a la tradición moderna: el primero, de José Manuel Pedrosa, profesor de la Universidad de Alcalá, sobre la pervivencia de la canción paralelística y algunos villancicos glosados antiguos en la tradición oral moderna de Asturias, Burgos, Portugal y Comunidades sefardíes; y el segundo, de Pedro Piñero, sobre la canción andaluza El carbonero, como ejemplo de canción en serie abierta de la lírica popular moderna, con el uso de formas métricas y enclaves temáticos de larga tradición, entre ellos los elementos de simbología sexual de los que tanto abunda.

Finalmente, como apéndice, aparece un estudio de Lourdes Pastor Pérez, profesora de la Universidad Autónoma de México, sobre la trayectoria histórica de la seguidilla, una forma poética eminentemente popular que marcó el paso de la tradición antigua a la moderna a finales del siglo XVI.

El libro se cierra con una Bibliografía general correspondiente a los estudios reunidos y con un Índice de primeros versos de los textos citados, elaborados ambos por Antonio José Pérez Castellano. El haber juntado todas las referencias bibliográficas de los distintos autores para ofrecer una única bibliografía final es uno de los grandes aciertos del libro, pues no sólo evita repeticiones sino que resulta de suma utilidad, en un tema tan poco transitado por la investigación $\mathrm{y}$, por tanto, tan necesitado de buenas orientaciones bibliográficas.

En efecto, por la poca bibliografía que hay sobre el tema de la lírica popular de tipo tradicional es por lo que este libro se convertirá en referencia inexcusable. Hay, sí, libros magistrales, como el Corpus de la antigua lírica de Margit Frenk (1987), estudios admirables como el de Antonio Sánchez Romeralo (1969) sobre El villancico o los de Eugenio Asensio (1957) y Margit Frenk (1971 y 1978) sobre el cancionero medieval y renacentista, y antologías extraordinarias como la de Dámaso Alonso y José Manuel Blecua (1956) y la de José María Alín (1968), pero todos ellos centrados en la lírica antigua. Muy pocos estudios abarcadores pueden citarse que atiendan a la lírica popular contemporánea: los de Eduardo M. Torner (1966), Carlos Magis (1964), Mercedes Díaz Roig (1976), modernamente José Manuel Pedrosa (1995) y pocos más, y éstos centrados sólo en aspectos muy concretos. Es cierto también que para que haya estudios amplios y abarcadores debe 
haber antes antologías amplias y sistemáticas que recojan la tradición poética de las distintas regiones folclóricas. Y en este terreno falta mucho por hacer, todavía, en España y más en el resto del Mundo Hispánico.

Es curioso que de los dos grandes géneros de que se nutre la poesía popular, el romancero y el cancionero, aunque los dos muy desdeñados por la investigación académica, refiriéndonos ahora sólo a la tradición moderna, el primero de ellos ha alcanzado un nivel de conocimiento muy estimable, tanto por lo que se refiere a la colección de textos recolectados directamente de la tradición como por los estudios que sobre ellos se han hecho, en cuya bibliografía están muchos de los más relevantes maestros de la filología española, empezando por el maestro de todos que fue Menéndez Pidal. Hoy puede decirse que son pocas las regiones (no hablamos aquí de "Comunidades Autónomas", que son divisiones político-administrativas modernas que en algunos casos no coinciden con las regiones naturales e históricas de España) o provincias de España (y de Portugal, otra cosa es el mundo americano y otra el mundo sefardí) que no tengan su particular Romancero moderno, además de contar con estudios teóricos generales y magistrales, como los de Don Ramón y los de Diego Catalán.

Sin embargo, la dedicación al cancionero moderno está todavía en un nivel muy insuficiente. Cierto es que, poco a poco y desde lugares muy diversos, van apareciendo Cancioneros locales y regionales, y esto es digno de ser destacado, aunque falten en algunos casos una metodología apropiada y una sistematicidad necesaria. Pero empiezan a formar una colección que debe tenerse en cuenta, por la ingente cantidad de poesía que en ellos se junta. Aparte las colecciones clásicas (pero antiguas) de cantos populares de Rodríguez Marín, de cantes flamencos de Machado y Álvarez (Demófilo) y de otros, y de los Cancioneros que prestaron más atención a la música que a la letra (caso de los de Kurt Schindler, Córdova y Oña, Bonifacio Gil, García Matos, Torner, Marazuela, etc.), quiero destacar los Cancioneros que se han dedicado a dar conocer los repertorios de poesía popular de Llanes (Cea Gutiérrez, 1978), de Priego (Alcalá Ortiz, 1990), de Doña Mencía (Jiménez Moreno, 1990), de Candeleda (Jiménez Juárez, 1992), de Galicia (Schubarth y Santamarina, 1987), de Castilla y León (Díaz Viana y Manzano, 1989), de León (Manzano, 1988-1991), de Murcia (Díez de Revenga, 1984, y Guerrero Ruiz y López Valero, 1996), de Canarias (Trapero, 1991), de Ávila (Tejero Robledo, 1994), de Granada (Escribano y otros, 1994), de Almería (González Aranda y otros, 1998), etc.

El rescate de la poesía de tradición oral moderna debe continuarse e incluso hacerse más sistemática, y deben publicarse cuantos más repertorios mejor, pero deben empezar en serio los estudios sobre ella, siguiendo los caminos ya trazados por unos pocos adelantados en este tema. Un nuevo tiempo se adivina en los estudios sobre la lírica popular, que sucederá o convivirá con los estudios sobre el romancero. La convocatoria de Encuentros como éste de Sevilla, y de Congresos como los que se han celebrado recientemente en Londres y en Alcalá, prometen una "edad dorada" para la Lírica (o Lira) mínima, como se le está empezando a llamar ahora en un acierto denominador. Y la publicación de sus Actas será tarea fundamental para lograr una difusión y un conocimiento de esas investigaciones, como fundamental es esta publicación del Encuentro de Sevilla. 